7-1991

\title{
Why Doesn't Society Minimize Central Bank Secrecy?
}

Karen K. Lewis

University of Pennsylvania

Follow this and additional works at: https://repository.upenn.edu/fnce_papers

Part of the Finance Commons, and the Finance and Financial Management Commons

\section{Recommended Citation}

Lewis, K. K. (1991). Why Doesn't Society Minimize Central Bank Secrecy?. Economic Enquiry, 29 (3), 403-415. http://dx.doi.org/10.1111/j.1465-7295.1991.tb00835.x 


\title{
Why Doesn't Society Minimize Central Bank Secrecy?
}

\begin{abstract}
Societies have incentives to design institutions that allow central bank secrecy. This paper illustrates two of these incentives. First, if society tries to constrain secrecy in one way, central bankers will try to regain lost effectiveness by building up secrecy in other ways. Therefore, we may wind up accepting types of secrecy that appear preventable because reducing them would lead to higher costs. Second, if the social trade-offs between policy objectives change over time, the public may directly prefer greater central bank secrecy so that it will be surprised with expansionary policies when it most desires them.
\end{abstract}

\section{Disciplines}

Economics | Finance | Finance and Financial Management 
NBER WORKING PAPERS SERIES

WHY DOESN'T SOCIETY MINIMIZE CENTRAL BANK SECRECY?

Karen $\mathrm{K}$. Lewis

Working Paper No. 3397

\author{
NATIONAL BUREAU OF ECONOMIC RESEARCH \\ 1050 Massachusetts Avenue \\ Cambridge, MA 02138 \\ July 1990
}

\begin{abstract}
For useful comments, I am grateful to three anonymous referees, to Richard Sweeney, and to Martin Evans, Jim Lothian, Thomas Mayer, Guido Tabellini and participants in seminars at Carnegie Mellon University and New York University. Most of the work in this paper was completed while I was a Visiting Scholar at the Federal Reserve Board of Governors and I am grateful for useful conversations with the economists in the International Finance Division. This paper is part of NBER's research program in International Studies. Any opinions expressed are those of the author and not those of the National Bureau of Economic Research.
\end{abstract}


NBER Working Paper \#3397

July 1990

WHY DOESN'T SOCIETY MINIMIZE CENTRAL BANK SECRECY?

ABSTRACI

Societles have incentives to design institutions that allow central bank secrecy. This paper 1llustrates these incentives in two ways. First, if society tries to constrain secrecy in one way, central bankers will try to regain lost effectiveness by bullding up secrecy in other ways.

Therefore, we may wind up accepting types of secrecy that appear preventable because reducing them would lead to higher costs. Second, if the social trade-offs between policy objectives change over time, the public may directly prefer greater central bank secrecy so that it will be surprised with expansionary policles when it most desires them.

Karen K. Lewis

National Bureau of Economic Research 1050 Massachusetts Avenue Cambridge, MA 02139 
Central banks have repeatedly revealed a preference for secrecy in conducting monetary policy. ' In the United States, for example, the Federal Reserve has shown its bias towards policy secrecy in a number of ways, ranging from delays in releasing the minutes of FOMC meetings to ambiguous policy statements at Congressional hearings. 1 Nevertheless, the degree of disclosure required by Congress and the court system does not appear to minimize central bank secrecy. Indeed, the Fed's right to limit disclosure of policy intentions was upheld in a recent supreme Court case. ${ }^{2}$ Furthermore, similar social tolerance of central bank secrecy appears in the banking institutions of other countries. Clearly, this degree of secrecy arises endogenously from the interaction between the behavior of the monetary authorities and the legal institutions that society places upon these authorities.

This paper provides two potential explanations for the phenomena that societies choose not to legally minimize central bank secrecy. First, when establishing instfutional disclosure requirements upon central banks, members of society recognize the tendency for central bankers to be secretive. This secrecy imposes costs upon members of society by making shifts in policy objectives more difficult to detect. Faced with this tendency, members of society set legal institutions that appear to require less disclosure because more restrictive laws would induce central bankers to become more secretive in other less informative ways. ${ }^{3}$

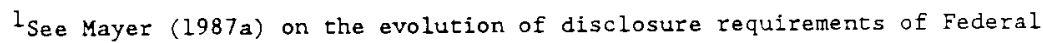
Reserve policy in the U.S.

${ }^{2}$ See Goodfrfend (1986) on Merrill vs. the FOMC.

${ }^{3}$ For example, as a lawsuit was threatening to force the Fed to publish the minutes of the FOMC meetings immediately following each meeting, the Fed decided to abolish the minutes altogether. See Mayer (1987), pages $13-15$ and $38-62$. 
Second, if the policy objectives that society finds desirable change over time, then members of society may difectly prefer some degree of central bank secrecy. Intuitively, secrecy allows central banks to conduct surprise policy actions in periods when on-average society most prefers them. For example, in periods when public opinion favors pushing down unemployment, central banks may conduct a surprise monetary expansion. ${ }^{1}$

The paper develops examples of each of these two effects using a discretionary equilibrium similar to that in Cukierman and Melezer (1986a). The desired trade-off between two policy objectives changes over time in response to changing political pressures. For the examples developed in this paper, the particular trade-off is between output and inflation. However, more generally, the basic results hold when the trade-offs between policy objectives vary over time. These policy objectives could include targets for real exchange rates or interest rates, for instance.

The plan of the paper is as follows. Section I describes the discretionary equilibritu given institutional settings for the conduct of monetary policy. Sections II and III describe examples of each of the two explanations for secrecy described above. Concluding remarks follow.

\section{The Degree of Polfcy Disclosure in a Discretionary Equilfbrium}

When the policy objectives of the monetary authorities shift over time due to changing economic or political circunstances, their choice of discretionary policy also shifts. ${ }^{2}$ In the absence of a mechanism to pre-commit to a particular

$1_{\text {This result reverses the causality to the arguement in cukierman and }}$ Meltzer (1986a) that central bankers ptefer secrecy in order to surprise output in periods when they care most about increasing output. Here, members of society prefer to be surprised by their own central banks.

${ }^{2}$ See, for example, Cukierman and Meltzer (1986a, 1986b). 
policy rule, the authorities will follow this shifting discretionary policy. Furthermore, since central bankers cannot precisely control the money supply, private market observers cannot directly observe the central bank's intended policy. The interaction between changing policy objectives by central banks. on the one hand, with incomplete private information about these objectives, on the other, yields an equilibrium policy process. In this equilibriun, market participants observe the money supply and other variables that are correlated with central banks objectives in order to form forecasts of fucure policy. In turn, central banks recognize that market participants are watching current money and other variables. They decide current policy based upon how this policy will affect future expectations, in addition to their current objectives. Within such a discretionary equilibrium, market participants implicitly observe some degree of central banker's policy intentions by watching variables correlated with policy.

But we must take this analysis one step backward if we want to ask how much central bank secrecy society would prefer in equilibrium. Addressing this question amounts to asking how society would choose the institutional environment where central banks operate. As described above, each institutional setting implies a particular discretionary equilibrium with a corresponding degree of implicit policy disclosure.

This question will be the focus of Sections II and II below. Before considering the secrecy issue, however, we must describe the discretionary equilibrium given a particular institutional framework. For this purpose, a discretionary equilibrium simllar to Gukierman and Meltzer (1986a) is briefly 
described next. ${ }^{1}$

The Central Bank's Objactives Given the Social Framework

As a policy-making entity, the government consists of many individuals with objectives that depend upon a desire to stay in office. Furthermore, the popularity of these government officials depend upon key economic variables that affect the well-being of their constituents. ${ }^{2}$ For example, an over-valued exchange rate worsens the competitiveness of the export industry, and high interest rates hurt the housing market as well as debtors. Therefore, government officials are influenced in their policy decisions by the effects of these policies upon special interest groups.

Although government objectives depend upon a number of different policy targets, we will take as an example the trade-off between two of them. Specifically, the auchorities would like to minimize inflation but also surpise inflation to reduce unemployment, as in Barro and Gordon (1983). In this case, the objective function of the central bank is given by:

(1) $w_{t}=x_{t}\left(m_{t}-E\left(m_{t} \mid I_{t-1}\right)\right)-\left(s_{s}\right)\left(m_{t}^{c}\right)^{2}$

where $m_{t}$ is the money supply at time $t, m^{c} t$ is the money supply intended by central bankers, $E\left(\mid I_{t}\right)$ is the expectations operator conditional upon the private sector's information set at time $t$, and $x_{t}$ is the time-varying tradeoff between the first and second components in $w_{t}$. The first component says that central bankers would like to push up money, $m_{t}$, for any given market forecast

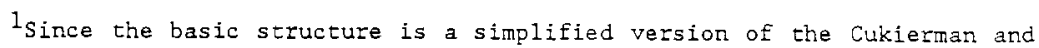
Meltzer (1986a) discretionary equilibrium, readers familiar with this model may wish to skim through to section II below.

2 The effects of unemployment and inflation upon public opinion about the state of the economy has been studied by Fischer and Huizinga (1982). The effects upon the popularity of the President is documented in Frey and Schneider (1978). 
of money, since nominal wage contracts incorporate expected inflation. A surprise expansion to the money supply thus induces a surprise fall in real wages and an increase in employment along the labor demand curve. The second component in (1) says that central bankers do not like inflation. 1 since the money supply is assumed to control inflation directly, the terms "money supply" and inflation will be used interchangeably.

Then, the time-varying parameter $x_{t}$ represents the authorities' desired trade-off between unemployment and inflationary targets. This trade-off varies through time due to changes in the distribution of income and political pover that influence politicians and, indirectiy, monetary authorities. Note that the objective function (l) is not a social welfare function. As in Cukierman and Meltzer (1986a), it represents the time-varying objectives of govermental authorities who influence the outcome of monetary policy. This policy derives Erom the objectives of governmental authorities, objectives that are not in general identical to those of society as a whole. 2

For the purpose of the examples, we will characterize the changing objectives of the monetary authorities according to the persistent process:
(2a) $x_{t}-A+P_{t}$
(2b) $P_{t}=\theta v_{t-1}+v_{t}$
$0<\theta \leq 1$,

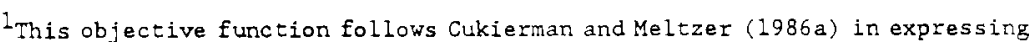
this component in terms of variations in the money control rather than the money supply itself. As they note, this will not affect the choice of discretionary policy since the authorities do not know the realization of the control error when they decide policy.

2 Two cases of social welfare functions will each be considered in Sections II and III, respectively. In this section, only the positive discretionary equilibrium is derived. 
where $v_{t}$ is a serially uncorrelated random variable with zero mean and constant variance, $\sigma_{v}^{2}$. The positive parameter, $A$, is known to the private sector and reflects the authorities unconditional trade-off for expanding output relative to reducing inflation. On the other hand, only the central bankers know the time-varying component, $P_{t}$, at each point in time. The disturbance, $v_{t}$, represents the most recent change in policy preferences, Pt.

The preference pattern described in (2) implies that changes in political trade-offs persist according to the autocorrelation parameter, $\theta$. This degree of persistence, in turn, depends upon social and legal institutional settings. For instance, the terms of political offices may overlap for individuals both. inside and outside the central bank who exert an influence on the authorities' policy-making process.

The simple form of policy preferences in (2) provides a very tractable and convenient solution to the discretionary equilibrium as will be shown below. Despite its utter simplicity, however, this formulation yields a rich variety of implications regarding the persistence of policy objectives. Specifically, the process for $\mathrm{Pt}$ in (2b) follows a first-order moving average process. According to this process, any current change in period t will also be correlated with the change in the following period at $t+1$. The variance of next period's policy, Pt+l, that can be explained by today's policy disturbance is just equal to $\theta /(1+\theta) .1$ Therefore, the autocorrelation in the policy process, $\theta$, captures the component of current policy preferences that will persist tomorrow. The discretionary equilibriun

As a result of central bank secrecy, monetary authorities maintain inside

1That is, the ratio of the variance of $P_{t+1}$ conditional upon $p_{t}$ over the total variance of $p_{t+1}$ equals $\operatorname{Var}\left(E\left(p_{t+1} \mid p_{t}\right)\right) / \operatorname{Var}\left(p_{t+1}\right)$ which equals $\theta /(1+\theta)$. 
information about their policy objectives. Therefore, private market participants can only watch variables correlated with these objectives to make inferences about policy. Put into the context of the objectives above, the market may observe the outcome of the money supply, $\pi_{t}$, but only the centrai bank knows its current objectives, $P_{t}$. Based upon the current private information set, market participants then try to detect $p_{t}$ in order to predict the outcome of future policy.

In order to provide a simple solution, we will assune that past disturbances to policy objectives, vt-k, are observed with some lag, $k$. Nevertheless, central bankers still have inside information since they alone know their current objectives, $v_{t}$, and therefore, $P_{t}$. This simplification is not necessary for the results obtained below but significantly streamlines the algebra. 1 Furthermore, this assumption may be reasonable for the Uiited States since the Fed publishes its "Directive" of the past Federal Open Market Committee meeting just prior to the current meeting.

For further simplicity, the lag when policy is revealed will be set equal to one. Therefore, the information set available to the private sector at the end of period t contains current and lagged money, and lags of policy objectives. That is, $I_{t}=\left\{\mathbf{m}_{t}, \mathbf{m}_{t-1}, \mathbf{m}_{t-2}, \ldots, v_{t-1}, v_{t-2}, \ldots\right\}$. In general, the information set may also contain other variables that are correlated with policy

$1_{\text {If }} v_{t}$ were never observed, then the forecast of policy objectives the following period would depend upon a backward-looking infinite series of the information set. Intuitively, agents would use the entire past history of the information in money to arive at an estimate of $v_{t-1}$. In a similar vein, Cukierman and Meltzer (1986a) treat the policy process as an auto-regressive process where the innovations are never observed so that agents must use an infinite ordered backward-filter to forecast future policy. Although these two specifications may add some realism to the discretionary equilibriun, assuming that the market detects policy innovations at a finite lag does not alter any of the basic results concerning central bank secrecy below. 
objectives. For example, in Section III, the information set will be expanded to include public opinion. Since the basic results remain when including these variables, we will first consider the shorter information set.

Given these objectives, the monetary authorities choose the money supply to maximize the discounted present value of eqn. (1). In other words,

$\infty$

(3) $\operatorname{Max} E\left(\Sigma \beta^{j} W_{t+j} \mid G_{t}\right)$

$m_{t}^{c} \quad j=0$

where $\mathrm{m}_{t}{ }^{\mathrm{c}}$ is the authorities' planned money supply and where $G_{t}$ is the government's information set at time $t$, that includes the government's current preferences; i.e., $G_{t}=\left\{v_{t}, v_{t-1}, \ldots\right\}$. Although future economic or political conditions are likely to have a high variance, the govermment has better information about this outcome since it has inside information about current policy.

The authorities can hide their current objectives because they cannot perfectly control the money supply. That is, any observation of the money supply differs from the authorities planned money supply according to control noise.

(4) $m_{t}=m_{t}^{c}+\phi_{t}$

where $\phi_{t}$ is a serially uncorrelated random variable with mean zero and variance $\sigma_{\phi}{ }^{2}$. Since the money supply cannot be controlled precisely, the variance of the control error has a lower bound so that $\sigma_{\phi} \geq \bar{\sigma}_{\phi}$, where $\bar{\sigma}_{\phi}$ is the minimun possible variance of the control error.

The private sector consists of an atomistic group of individuals who form rational expectations about the money supply. As will be shown below, the private sector's expectations are rational when they believe that the authorities use the following rule to conduct monetary policy: 
(5) $m_{t}^{c}=B_{0} A+B_{1} v_{t}+B_{2} v_{t-1}$,

where the $B_{i}$ are constant coefficients that will be determined in equilibrium. Substituting (5) into (4) and taking expectations implies,

(6) $E\left(m_{\tau} \mid I_{t-1}\right)=B_{0} A+B_{2} E\left(v_{t-1} \mid I_{t-1}\right)$.

As the appendix shows, the conditional expectation of the past policy disturbance, $v_{t-1}$, based upon the private information set equals,

(7) $E\left(v_{t-1} \mid I_{t-1}\right)=a\left(m^{c}{ }_{t-1}-B_{0} A-B_{2} v_{t-2}+\phi_{t-1}\right)$, where $a=\left[B_{1} \sigma_{v}^{2} /\left(\sigma_{\phi}^{2}+B_{1}^{2} \sigma_{v}^{2}\right)\right]$.

As quick inspection of (4) and (5) verifies, private agents observe the composite term in parentheses in eqn. (7) but not its components. Further substisuting (7) into (6) above provides the function that private agents use to forecast government policy:

(8) $E\left(m_{t} \mid I_{t-1}\right)=B_{0} A+B_{2} a\left(m^{c}{ }_{t-1}-B_{0} A-B_{2} v_{t-2}+\phi_{t-1}\right)$

Hence, although agents cannot directly observe the money supply intended by the authorities, $m^{c}{ }_{t-1}$, their forecast of future policy depends implicitly upon this variable according to the parameter, a.

The authorities recognize that their choice of money affects the market's forecasts as described in (8). Therefore, in maximizing their own objectives in (3), they view eqn. (8) as a constraint. Substituting (8) into (3) and maximizing with respect to $\mathrm{m}^{\mathrm{c}}{ }_{t}$ yields the following first-order condition.

(9) $\mathrm{m}^{\mathrm{c}} \mathrm{t}_{\mathrm{t}}-\mathrm{x}_{\mathrm{t}}-\beta a \mathrm{~B}_{2} \mathrm{E}\left(\mathrm{x}_{\mathrm{t}+1} \mid \mathrm{G}_{\mathrm{t}}\right)=\left(A+\mathrm{v}_{t}+\theta \mathrm{v}_{\mathrm{t}-1}\right)-\beta a \mathrm{~B}_{2}\left(A+\theta \mathrm{v}_{\mathrm{t}}\right)$.

This equation provides the equilibrium response of the government given the market's beliefs. The central bankers know their own objectives at time $t$, but have only a forecast about their objectives the next period. At each point in time, they would like to set their money supply equal to the current period trade-offs, $x_{t}$. However, they know that fully responding to these policy 
preferences will reveal them to the private sector according to a $B_{2}$. Therefore, they do not fully respond to their desired policy every period.

To find the equilibrium, we must equate the private sector's beliefs about government policy in eqn. (5) to the government's actual policy given. private beliefs in eqn. (9). This provides the equilibrium levels of the coefficients: (10a) $B_{0}=\left(1-\beta \theta a\left(B_{1}\right)\right)$

(10b) $B_{1}-\left(1-\beta \theta^{2} a\left(B_{1}\right)\right)$

(10c) $B_{2}=\theta$.

As these equations indicate, $B_{0}$ and $B_{1}$ depend upon the expectations coefficient, $a\left(B_{1}\right)$, which in turn depends upon $B_{1}$. Therefore, $B_{1}$ determines the rest of the equilibrium. To focus upon choice variables but without loss in generality, the rate of time preference, $\beta$, will be set equal to one throughout the remaining analysis.

Figure 1 iliustrates the solution of $B_{1}$ in terms of the intersection between market beliefs from eqn. (5) and the actual policy from eqn. (10). The vertical axis shows the rule that the authorities actually follow as a function of $B_{1}$, given by the right-hand side of ( $10 \mathrm{~b}$ ). For given variances, $\sigma_{\mathrm{v}}$ and $\sigma_{\phi}$, the policy function is described by the bold line labeled $1-\theta^{2} a\left(B_{1}, \ldots\right)$ and is minimized at $\widetilde{\mathrm{B}}=\left(\sigma_{\mathrm{V}} / \sigma_{\phi}\right)$. This function intersects with the private market's beliefs, $B_{1}$, at point $B_{1}{ }^{*}$. The equilibrium between private market's beliefs and government objectives ties down the discretionary equilibrium.

This equilibrium contains an implicic degree of disclosure, or conversely secrecy, about the policy objectives by the monetary authorities. The degree of variability in the market's forecast of policy provides a useful measure of this inherent secrecy. Using the equilibrium solutions in (10) above to calculate this conditional variance, the degree of secrecy inherent in any 
discretionary equilibrium may be written: ${ }^{1}$

$$
\left.S=-E\left(m_{t}^{c}-E\left(m_{t}^{c} \mid I_{t}\right)\right)^{2}\right\}-S\left(\theta, \sigma_{\phi}\right) \text {. }
$$

Thus, how much of the current policy objectives can be detected by private agents depends both upon (a) the persistence of policy objectives, deterring authorities from reacting to their current preferences, and upon (b) the degree of monetary noise, allowing authorities to hide their current policy actions. But these variables are not arbitrarily determined. Rather, they are the product of choices made when designing the institutions for conducting monetary policy. To ask how these institutions would be chosen along with their implied level of secrecy, we will consider two different social objective functions in the next two sections.

\section{Section II. Secrecy when Society Prefers Stable Policy}

Suppose first that society as a whole prefers a stable trade-off between unemployment and inflation with an objective function given by:

(12) $U_{t}=\left(m_{t}-E\left(m_{t} \mid I_{t}\right)\right) A+h\left(m_{t}{ }^{c}\right)^{2}$

The difference between the policy-makers objectives and society-as-a-whole's objectives can be seen by comparing eqn. (12) with eqn. (1). In (1), policymakers are influenced by individuals such as small interest groups or particular members of the FOMC. These individuals comprise only an infinitesimal fraction of overall society so that their preferences do not appear in the social objective function (12). ${ }^{2}$

${ }^{1}$ Algebraically, this conditional variance is $\left(B_{1}{ }^{2}+\theta^{2}\left(1-a\left(B_{1}\right) B_{1}\right)^{2}\right) \sigma_{\mathrm{V}}{ }^{2}$ - $a\left(B_{1}\right)^{2} \theta^{2} \sigma_{\phi}^{2}$ and thus depends upon the parameters, $\theta, \sigma_{\mathrm{v}}$ and $\sigma_{\phi}$. Since the variability of monetary noise and persistence in policy will be the focus of the analysis below, the variability of policy preferences are subsumed in eqn (11).

${ }^{2}$ The case where these groups are large enough to affect social welfare appears in Section III below. 
From society's point of view, the discretionary equilibrium in section I above imposes costs arising from the variability of policy. The absence of a mechanism to force central bankers to commit to a stable policy rule implies that the authorities will follow the discretionary policy. However, some discretionary equilibria are socially preferable to others as the expected value of the social objective function under discretionary policy illustrates. In particular, substituting the private sector money supply beliefs from (5) into (12) and taking expectations yields,

(13) $\left.E\left(U_{t}\right)=-3 / B_{0}^{2} A^{2}+\left(B_{1}^{2}+B_{2}^{2}\right) \sigma_{v}^{2}\right]$.

This cost arises from two components that depend in turn upon $A$, the unconditional tendency of the authorities to inflate, and upon $\sigma_{v}$, the variability of policy shifts. Specifically, the first component, $b_{2} B_{0}{ }^{2} A^{2}$, gives the dead-reight loss of a suboptimally high inflation level. The persistence of policy deters the authorities from expanding so that the unemployment trade-off term, A, is multiplied by a number less than one; i.e., $B_{0}=\left(1-a \theta<1\right.$. By contrast, the second component, $x_{2}\left(B_{1}^{2}+B_{2}^{2}\right) \sigma_{v}^{2}$, captures the effects of changing policy objectives upon the inflation variance. other things equal, more variability in policy pressures by special interest groups induces greater variability in monetary policy, and, therefore, higher costs to society as a whole.

Although the nature of discretionary governmental policy imposes these social costs, society can nevertheless influence the behavior of discretionary goverment policy by its choice of the institutional environment. The degree of policy persistence can be affected by a number of different social and legal institutions that promote longer terms or overlaps of office for governmental officials. For example, the U.S. Banking Act of 1935 instituted 14 year cerms 
of appointment for Federal Reserve Governors with a turnover of one governor every 2 years. The purpose of the measure was to make smoother policy transitions and also to reduce the governors' dependence upon the President who has a shorter term of office. The average turnover in the governorship positions has been about 7 years.

Thus, if society could choose the rate of policy persistence to minimize the costs of discretionary policy, how much persistence would it choose? This question may be answered by considering a social planner at the beginning of time who maximizes equation (13) with respect to $\Theta$. This maximization is proven in the appendix and implies the following result:

Result 1: For a given degree of policy noise, $\sigma_{\phi}$, the optimal degree of persistence in policy objectives is the highest persistence possible: $\theta^{*}=1$.

Intuitively, we can see from eqn. (13) above that a change in persistence will implicitly affect social welfare both through the level and the variance of inflation. Figure 1 illustrates the effects of changing $\theta$ upon the equilibrium levels of $B_{1}$ and, hence through $(10 a), B_{0}$. A rise in $\theta$ to $\theta_{1}>\theta_{0}$ will shift down the government's reaction function, $1-\theta^{2} a(\cdot)$ at every level of $B_{1}$. This implies a lower level of equilibrium $B_{1}$ at $B_{1 b}{ }^{*}<B_{1 a}{ }^{*}$, and therefore less reaction to current policy objectives and a lower level of $B_{O}$. This deterrent upon changing policy implies both a lower level of inflation through $B_{0}$, and a lower variance of inflation through $B_{1}$. For both reasons, society would prefer policies that induce greater policy persistence.

The Government's Desire for Secrecy

Given the degree of policy noise inherent in the monetary operating procedure, the result above says that society would set up iristitutions that fostered the greatest policy persistence possible. However, given greater 
stability of tenure in office, policy-makers may choose operating procedures that further obfuscate their policy intentions. To consider how the welfare of policy-makers depends upon their ability to hide policy intentions, we may calculate their expected utility by substituting eqn. (5) into eqn. (1) and taking expectations:

(14) $E\left(\omega_{t}\right)=-\left[B_{0}^{2} A^{2}-\left(B_{1}^{2}+B_{2}^{2}\right) \sigma_{y}^{2}\right]$

Comparing (14) to (13) reveals how the objectives of the authorities differ from those of society as a whole. The first term in brackets depends upon the average level of inflation, $B_{0} A$, and represents the inflation cost to both central bankers and society. However, by the second term, $\left(B_{1}{ }^{2}+B_{2}{ }^{2}\right) \sigma_{v}{ }^{2}$, the central bankers gain from the variability of policy while society loses. To see why, note from (5) that the authorities react to their current preferences according to the coefficients $\mathrm{B}_{1}$ and $\mathrm{B}_{2}$. However, current preferences, $\mathrm{P}_{t}$, are correlated in equilibrium with the forecast error by private agents, ( $m_{t}-E\left(m_{t}\right.$ $\left.I_{t-1}\right)$. Therefore, the authorities gain from being able to on-average surprise the market with a monetary expansion during the periods when the authorities most care about increasing output. However, this variation in policy is always costly from a social viewpoint.

As Cukierman and Meltzer (1986a) show, central bankers may prefer greater monetary noise, $\sigma_{\phi}$, so they can surprise the market with monetary expansions in periods when they most care about stimulating the economy. Intuitively, monetary noise allows the authorities to be ambiguous about their policy intentions and to produce a greater shock to the economy when $p_{t}$ is large. By determining the monetary policy environment, such as in the choice of operating procedures, they influence the degree of noise inherent in the money supply process. What level of noise would the authorities choose? Maximizing eqn. (14) with respect to $\sigma_{\phi}$ 
for a given level of persistence, $\theta$, yields a second result and is proven in the appendix.

Result 2: For a given degree of policy persistence, the authorities would choose a higher $\sigma_{\phi}{ }^{*}$ than the minimum possible variance. Furthermore, the optimal variance, $\sigma_{\phi}{ }^{*}$, increases wh policy persistence, $\theta$.

Intuitively, the higher the noise in monetary error, the more the authorities can hide their current policy objectives, and the more on-average they can gain from surprise expansions.

Society's Choice of Persistence When Central Banks are Secretive

The result above indicates that central bankers would prefer to be more secretive, given a process for policy shifts, However, in developing institutions for conducting monetary policy, society recognizes this tendency toward secrecy. Therefore, instead of simply choosing institutions that promoce policy persistence given the noisiness of central bank policy, as in Result 1 , society incorporates the choices made by central banks, as in Result 2, into their decision of policy design.

In terms of the example above, we can address this issue by asking: how would a social planner's choice of policy persistence change when he realizes that central banks will choose ambigulty based upon this persistence. More specifically, totally differentating equation (14) with respect to $\theta$ and incorporating Result 2 implies:

$(\mathrm{dE}(\mathrm{U}) / \mathrm{d} \theta)=\left.(\mathrm{dE}(\mathrm{U}) / \mathrm{d} \theta)\right|_{\sigma \phi}+\left(\mathrm{dE}(\mathrm{U}) / \mathrm{d} \sigma_{\phi}\right)\left(\mathrm{d} \sigma_{\phi}{ }^{*} / \mathrm{d} \theta\right)$.

Result 1 said that society would maximize utility by the first term on the righthand side, holding $\sigma_{\phi}$ constant. However, Result 2 says that ambiguity increases with the persistence; or, $\left(\mathrm{d} \sigma_{\phi}{ }^{*} / \mathrm{d} \theta\right)>0$. On the other hand, social welfare falls as the variance of policy increases, i.e., $\left(d E(U) / d \sigma_{\phi}\right)<0$. Therefore, 
although greater policy persistence reduces variability and hence improves social welfare through the first term, it also prompts central bankers to conceal their policies, reducing welfare through the second term. This relationship leads to the following result:

Result 3: Soclety chooses a lower rate of policy persistence when the govermment decides the degree of pollcy amblgutty based upon this persistence.

The result is formally derived in the appendix.

The example in this section also illustrates a more general point. If society tries to constrain secrecy in one way, central bankers will try to regain lost effectiveness by building up secrecy in other ways. This means that in the design of social institutions, account must be taken of the central bank's reactions to any constraints on secrecy. We may therefore wind up accepting types of secrecy that appear preventable because eliminating them or reducing them would lead to higher costs due to the Fed's reaction.

III. Secrecy then Soclety Prefers Discretionary Policy

then social preferences for policy objectives change over time, society may directly find more central bank secrecy desirable. Thus, suppose that instead of (13), social objectives can be written:

(15) $U_{t}=\left(m_{t}-E\left(m_{t} \mid I_{t-1}\right)\right)\left(A+u_{t}\right)-\frac{1}{2}\left(m_{t} c\right)^{2}$

where $u_{t}=e_{t}+\mu e_{t-1}$. That is, public opinion about the importance of unemployment relative to inflation changes over time according to $u_{t}$. This variable follows a first-order moving average process as in the authorities objectives (2). Furthermore, since changing social opinion about economic tradeoffs influences the authorities' popularity, shifts in public opinion are correlated with shifts in government policies; i.e., $E\left(v_{t} e_{t}\right)-\sigma_{v e}>0$.

Therefore, private agents have an additional piece of information about 
policy intentions since they know public opinion. As a result, the private sector's information set every period now includes the most recent state of public opinion, et, so that:

$I_{t} \equiv\left(m_{t}, m_{t-1}, m_{t-2}, \ldots, e_{t}, e_{t-1}, \ldots, v_{t-1}, v_{t-2}, \ldots\right)$.

In this case, the discretionary solution appears the same as described in section I except that the market's prediction of the policy preferences now depends upon public opinion as well. Instead of (7), we have:

$$
E\left(v_{t-1} \mid I_{t-1}\right)=a\left(m_{t-1} c-B_{0} A-B_{2} v_{t-2}+\phi_{t-1}\right)+b e_{t}
$$

where now $\mathbf{a}<\mathbf{a}$. In other words, since agents have information about policy preferences in addition to the money supply alone, they pay relatively less attention to money when making forecasts. Substituting this forecast of policy preferences into the money supply forecast, the discretionary equilibrium can be calculated with the same steps as in Section I. Further substituting the money supply beliefs in (5) into the objective function (16) gives the expected value of social welfare as,

$$
E\left(U_{t}\right)=-\left[B_{0}^{2} A^{2}+\left(B_{1}^{2}+B_{2}^{2}\right) \sigma_{v}^{2}\right]-b_{2}^{2} \sigma_{e}^{2}+\left(B_{1}^{2}+B_{2}^{2}\right) \sigma_{v e} .
$$

The first term in brackets is the same as in eqn (13). The second term represents the cost arising from periods when society would prefer more monetary stimulation. However, the last term increases social welfare due to the covariance between public opinion and the preferences of central bankers. Intuitively, during periods when society cares most about stimulating the economy, the authorities do too. However, since the authorities preferences are not perfectly correlated with the public's preferences, the public will be onaverage surprised by expansions during these periods.

Since greater obfuscation of policy allows central banks to carry out these surprise expansions, society may actually prefer greater ambiguity in the form 
of greater monetary noise. More formally, differentiating (17) with respect to $\sigma_{\phi}$ demonstrates that whether society directly prefers more secrecy depends upon which of two effects dominates. An increase in the degree of noise improves social welfare by conducting surprise expansions when society cares most about them. However, an increase in the variance of the monetary control noise makes people pay less attention to the money supply when making forecasts, thereby reducing the authorities' ability to conduct surprise inflation in the first place. Overall, when the benefits to surprise policy dorninate the loss in information from the money supply, society will prefer to be less informed about policy intentions.

\section{Concluding Remarks:}

This paper has motivated with two examples why societies allow central banks to remain secretive about their policy intentions. First, when society prefers stable policy but monetary authorities respond to the changing influence of interest groups, society can induce the central bankers to smooth the monetary policy process through institutions that promote greater policy persistence. However, this action also increases the government's incentive to choose a policy process with greater noise and, therefore, more secrecy. Since members of society recognize this incentive, they prefer to choose institutions that appear to allow greater secrecy. Second, when society's own relative trade-offs change over time, society may directly prefer that the central bank maintain secrecy in order to conduct surprise monetary expansions during periods when the public on-average prefers more economic stimulation. Although the analysis in this paper has investigated these two extreme motivations for central bank secrecy, the actual reasons are likely to be a combination of both factors. 


\section{References}

Barro, Robert J., and David B. Gordon, "Rules, Discretion and Reputation in a Model of Monetary Policy," Joumal of Monetary Economics, July 1983, 101122.

Cukierman, Alex, and Allan H. Meltzer, "A Theory of Ambiguity, Credibility, and Inflation Under Discretion and Asymetric Information," Econometrica, September 1986a, 1099-1128.

Cukierman, Alex, and Allan H. Meltzer, "A Positive Theory of Discretionary Folicy, the Cost of a Democratic Government, and the Benefits of a Constitution,"." Economic Inquiry, July 1986b, 367-388.

Fischer, Stanley, and John Huizinga, "Inflation, Unemployment, and Public Opinion Polls," Joumal of Money, Gredit, and Banking, February 1982, I - 19. Frey, Bruno, and Friedrich Schneider, "An Empirical Study of Politico-Economic Interactions in the U.S.," Review of Economics and Staristics, May 1978, $174-183$.

Goodfriend, Marvin, "Monetary Mystique: Secrecy and Central Banking," JournaI of Monetary Economics, January 1986, 63-92.

Mayer, Thomas, "Disclosing Monetary Policy," Monogram Series in Finance and Economics, Salomon Brothers Center for the Study of Financial Institutions, New York University, 1987.

\section{Appendix A: Solving the Market's Forecast Problem}

Section I: In order to calculate $E\left(v_{t-I} I_{t-1}\right)$ in eqn. (7), the market observes $m_{t-1}$ and its known components from (4) and (5): $B_{0} A$ and $B_{2} v_{t-I}$. Therefore, 
they observe:

$$
m_{t-1}-B_{0} A-B_{2} v_{t-2}-B_{1} v_{t-1}+\phi_{t-1} .
$$

Hence, $E\left(v_{t-1} I_{t-1}\right)=a\left(B_{1} v_{t-1}+\phi_{t-1}\right)$ where $a$ is the minimum mean squared error forecast coefficient. In other words, a is defined by:

Min $\left[E\left(v_{t-1}-a\left(B_{1} v_{t-1}+\phi_{t-1}\right)\right)^{2}\right]$.

a

Carrying out this minimization gives the solution of a as:

$$
\mathrm{a}=\left[\mathrm{B}_{1} \sigma_{\mathrm{v}}^{2} /\left(\sigma_{\phi}^{2}+\mathrm{B}_{1}^{2} \sigma_{\mathrm{v}}^{2}\right)\right] \text {. }
$$

Including in the minimization above other variables such as lagged $v_{t-k}$ for $k$ $>$ I yields coefficients equal to zero. Intuitively, since lagged policy shifts are uncorrelated with policy shifts beyond one period, knowledge of these shifts are not useful for forecasting future policy.

Section III. When the market observes the public opinion, $e_{t}$, as in (16), their forecast of $v_{t-1}$ now incorporates this variable. Therefore,

$$
\begin{aligned}
& E\left(v_{t-1} \mid I_{t-1}\right)-\tilde{a}\left(B_{1} v_{t-1}+\phi_{t-1}\right)+\tilde{b}_{t} e_{t} \\
& \text { where } \tilde{a}=\left[B_{1}\left(\sigma_{v}{ }^{2}-\left(\sigma_{v e}{ }^{2} / \sigma_{e}{ }^{2}\right)\right) /\left(\sigma_{\phi}{ }^{2}+B_{1}{ }^{2}\left(\sigma_{\mathrm{v}}{ }^{2}-\left(\sigma_{\mathrm{ve}}{ }^{2} / \sigma_{e}{ }^{2}\right)\right)\right)\right] \\
&\text { and } \left.\left.\ddot{b}=\left[\sigma_{\mathrm{ve}} \sigma_{\phi}{ }^{2}\right)\right) /\left(\sigma_{\phi}{ }^{2}+\mathrm{B}_{1}{ }^{2}\left(\sigma_{\mathrm{v}}{ }^{2}-\left(\sigma_{\mathrm{ve}}{ }^{2} / \sigma_{\mathrm{e}}{ }^{2}\right)\right)\right)\right] .
\end{aligned}
$$

Clearly, $\tilde{a}<$ a above. 
Appendix B: Results in the Text

Showing the results in the text depends upon the following facts.

Fact 1: $0<\left(\partial a / \partial B_{1}\right)<1$.

Proof: $\quad\left(\frac{\partial \mathrm{a}}{\partial \mathrm{B}_{1}}\right)=\left[\frac{\sigma_{\nu}^{2}\left(\sigma_{\phi}^{2}-\mathrm{B}_{1}^{2} \sigma_{\nu}^{2}\right)}{\left(\sigma_{\phi}^{2}+\mathrm{B}_{1}^{2} \sigma_{\nu}^{2}\right)^{2}}\right]$

The first part is immediate since $\operatorname{sign}\left(\partial a / \partial B_{1}\right)-\operatorname{sign}\left(\sigma_{\phi}^{2}-B_{1}^{2} \sigma_{\nu}^{2}\right)>0$. For the second part, note that if $\left(a a / \partial B_{1}\right)<1$, then:

$\sigma_{\nu}^{2}\left(\sigma_{\phi}^{2}-B_{1}^{2} \sigma_{\nu}^{2}\right)<\left(\sigma_{\phi}^{2}+B_{1}^{2} \sigma_{\nu}^{2}\right)^{2}$

But, $\sigma_{\phi}^{2}-B_{1}^{2} \sigma_{\nu}^{2}<\sigma_{\phi}^{2}+B_{1}^{2} \sigma_{\nu}^{2}$

and, $\sigma_{\phi}^{2}+B_{I}^{2} \sigma_{\nu}^{2} \geq \sigma_{\nu}^{2}+B_{I}^{2} \sigma_{\nu}^{2}=2 \sigma_{\phi}^{2}>\sigma_{\nu}^{2}$.

Therefore, $\left(\partial a / \partial B_{1}\right)<1$.

Fact 2: $a=\left\{a: B_{I}=\left(I-\theta^{2} a\right), a-\sigma_{\nu}^{2} B_{1} /\left(\sigma_{\phi}^{2}+B_{1}^{2} \sigma_{\nu}^{2}\right)\right\}$ is (i) strictly decreasing and (ii) convex in $\theta$ for $\theta \in(0,1)$.

Proof: Since $(\mathrm{da} / \mathrm{d} \theta)=(\partial \mathrm{a} / \partial \theta)\left(\mathrm{dB}_{1} / \mathrm{d} \theta\right)$, substitute the definition of $a\left(B_{1}\right)$ from eqn. (7) into the equilibrium condition (10b) and totally differentiate with respect to $B$ and $\theta$. Part (i) is immediate, since, $\left(\frac{\mathrm{d} a}{\mathrm{~d} \theta}\right)=\left(\frac{\partial \mathrm{a}}{\partial \theta}\right)\left(\frac{\mathrm{dB}}{\mathrm{d} \theta}\right)=-2 \mathrm{a}\left[\frac{\theta\left(\partial \mathrm{a} / \partial \mathrm{B}_{1}\right)}{1+\theta^{2}\left(\partial \mathrm{a} / \partial \mathrm{B}_{1}\right)}\right]$

and since $\left(\partial a / \partial B_{1}\right)>0$ by Fact 1 . 
Part (ii) can be established by differentiating ( $\left.d a / d B_{1}\right)$.

$\left(\frac{d^{2} a}{(d \theta)^{2}}\right)=-2 a\left[\frac{\partial\left(\partial a / \partial B_{1}\right)}{\left(1+\partial\left(\partial a / \partial B_{1}\right)-2\right.}\left[2\left(1-\theta(1-\theta)\left(\partial a / \partial B_{1}\right)\right)+\theta\left(\partial a / \partial B_{1}\right)\right)\right]<0$.

where the inequality follows since by Fact $1,(\partial a / \partial B)<1$.

Fact 3: $a=\left\{a: B_{1}=\left(1-\theta^{2} a\right), a=\sigma_{\nu}^{2} B_{1} /\left(\sigma_{\phi}^{2}+B_{1}^{2} \sigma_{\nu}^{2}\right)\right\}$ is strictly decreasing in $\sigma_{\phi}$.

Proof: Since $\left(\mathrm{dB}_{1} / \mathrm{d} \sigma_{\phi}\right)=-\theta^{2}\left(\mathrm{da} / \mathrm{d} \sigma_{\phi}\right)$, it is sufficient to show that $\mathrm{B}_{1}$ is increasing in $\sigma_{\phi}$. But, differentiating the equilibrium condition, (10b) implies:

$\left(\frac{\mathrm{dB}}{\mathrm{d} \sigma_{\phi}}\right)=-\left[\frac{\theta^{2}\left(\partial \mathrm{a} / \partial \sigma_{\phi}\right)}{1+\theta^{2}\left(\partial \mathrm{a} / \partial \mathrm{B}_{1}\right)}>0\right.$

where the inequality follows since $\left(\partial a / \partial B_{1}\right)>0$ from Fact 1 and since $\left(\partial a / \partial \sigma_{\phi}\right)<0$ by inspection.

Proof to Result 1: It is sufficient to show that $\left(\frac{\mathrm{dE}(\mathrm{U})}{\mathrm{d} \theta}\right)>0$ for $\theta \varepsilon(0,1)$. But, $\left(\frac{\mathrm{dE}(\mathrm{U})}{\mathrm{d} \theta}\right)=\sigma_{\nu}^{2}\left[\left(\mathrm{~B}_{1} \theta+\mathrm{K}^{2} \mathrm{~B}_{0}\right)\left(\mathrm{a}+\theta\left(\frac{\mathrm{da}}{\mathrm{d} d}+\theta \mathrm{aB}_{1}+\theta^{2}\right]\right.\right.$, where $\mathrm{K}=\left(\mathrm{A} / \sigma_{\nu}\right)$, so that $\mathrm{a}+\theta(\mathrm{da} / \mathrm{d} \theta)>0$ is a sufficient condition for $(\mathrm{E}(\mathrm{U}) / \mathrm{d} \theta)>$ 0 . But by Fact 2, a is strictly decreasing in $\theta$ while $|(\mathrm{da} / \mathrm{d} \theta)|$ is strictly increasing in $\theta$. Thus, the sufficient condition holds if at $\theta=1$, $(\theta / a)|(d a / d \theta)|=2\left[\frac{\left(\partial a / \partial B_{1}\right)}{1+\left(\partial a / \partial B_{1}\right)}\right]<1$, which is immediate since by Fact $1,\left(\partial a / \partial B_{1}\right)<1$. 
Proof to Result 2: Differentiating the unconditional expectation of the authorities objective function, eqn. (14), with respect to $\sigma_{\phi}$ implies:

$\left(\mathrm{dE}\left(\mathrm{W}_{t}\right) / \mathrm{d} \sigma_{\phi}\right)=-\theta\left(\sigma_{\nu}^{2} \mathrm{~B}_{1} \theta-\mathrm{A}^{2} \mathrm{~B}_{0}\right)\left(\mathrm{da} / \mathrm{d} \sigma_{\phi}\right)$

We will next consider two cases:

(i) When $\sigma_{\theta}^{2}>A^{2}$ : Since $\left(B_{1} / B_{0}\right)>I$ and $\left(\mathrm{da} / \mathrm{d} \sigma_{\phi}\right)<0$ by Fact 1 , we have the result that $\left(\mathrm{dE}\left(\mathrm{H}_{t}\right) / \mathrm{d} \sigma_{\phi}\right)>0$ at every equilibrium level of $\mathrm{B}_{1}$ and $\mathrm{B}_{0}$. Therefore, the highest possible noise variance is optimal.

(ii) When $\sigma_{\theta}^{2}<A^{2}$, the optimal value of $\sigma_{\phi}$ is where $\left(\mathrm{dE}\left(\mathrm{W}_{t}\right) / \mathrm{d} \sigma_{\phi}\right)=0$ as can be verified by checking the second order conditions. Solving the first order condition in terms of $B_{1}$ implies:

$$
B_{1}^{*}=\frac{A^{2}(1-\theta)}{\sigma_{\nu}^{2}\left(A^{2}-\theta^{2} \sigma_{\nu}^{2}\right)}
$$

Subsituting this value into the authorities' objective function (14) and totally differentiating with respect to $\theta$, it is straightforward to show that: $\left(\partial \sigma_{\phi}^{*} / \partial \theta\right)>0$.

\section{Proof to Result 3}

The total differential of (13), society's preferences, from a change in persistence is given by:

$$
\left(\frac{\mathrm{dE}(\mathrm{U})}{\mathrm{d} \theta}\right)=\left.\left(\frac{\mathrm{dE}(\mathrm{U})}{\mathrm{d} \theta}\right)\right|_{\sigma_{\phi}}+\left(\frac{\mathrm{dE}(\mathrm{U})}{\mathrm{d} \sigma_{\phi}}\right)\left(\frac{\mathrm{d} \sigma_{\phi}}{\mathrm{d} \theta}\right)
$$


From Result 1, (dE $(\mathrm{U}) / \mathrm{d} \theta)\left.\right|_{\sigma_{\phi}}>0$, so that welfare is always increasing in $\theta$. However, also by Result 1, $\left(d \sigma_{\phi}^{*} / d \theta\right)>0$. Differentiating eqn. (13) with respect to $\sigma_{\phi}$ implies:

$$
\left(\frac{\mathrm{d} E(\mathrm{U})}{\mathrm{d} \sigma_{\phi}}\right)=\theta \sigma_{\mathrm{v}}^{2}\left(\mathrm{~K}^{2} \mathrm{~B}_{0}+\theta \mathrm{B}_{1}\right)\left(\frac{\mathrm{da}}{\mathrm{d} \sigma_{\phi}}\right)
$$

where again $K=\left(\mathrm{A} / \sigma_{\nu}\right)$. From Fact $3\left(\mathrm{da} / \mathrm{d} \sigma_{\phi}\right)<0$ so that $\left(\mathrm{dE}(\mathrm{U}) / \mathrm{d} \sigma_{\phi}\right)<0$. Therefore, society would prefer a lower level of persistence in policy objectives than when $\left(d \sigma_{\phi}^{*} / d \theta\right)=0$. 


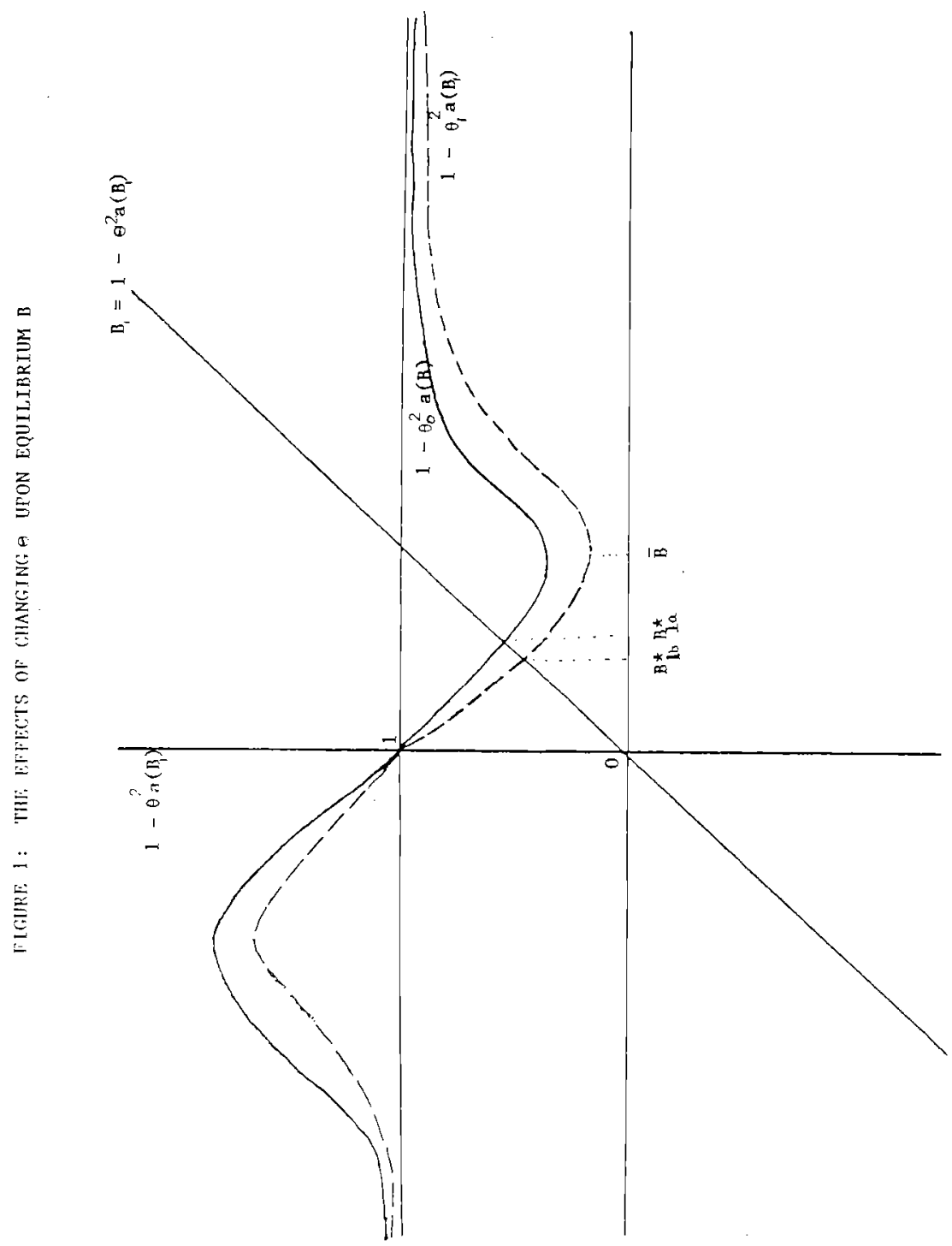

